\title{
RELEVANSI NILAI INFORMASI AKUNTANSI ALTERNATIF SERTA IMPLIKASINYA TERHADAP PROSES PENGAMBILAN KEPUTUSAN INVESTASI DENGAN MENGGUNAKAN SEQUENTIAL EXPLANATORY MIXED METHOD
}

\author{
Mada Purwanto Wahyu Nugroho', ${ }^{1)}$ Ahmad Syifaudin ${ }^{2)}$ \\ Universitas Swadaya Gunung Jati \\ Email :purwantown@yahoo.com; ahmad.syifaudin@gmail.com
}

\begin{abstract}
Distortion of information is one of the inherent accounting risks in financial statements. Financial statements are one of the fundamental sources of information that can be used in investment decision making in the Indonesia stock exchange. If investors use this information, then investors also have the same risk that is the distortion of information contained in financial statements. This research tries to test whether stock prices can be more explained through alternative accounting information or information contained in financial statements. This research was conducted using a sequential explanatory mixed method. Using data on companies listed in the Business 27 index, tested using path analysis through multiple regression models, the results of this research indicate that alternative accounting information has not been able to explain variations in stock price changes compared to accounting information contained in financial statements. Meanwhile, the results of the analysis using qualitative data indicate there is a match between the results of quantitative analysis and qualitative analysis.
\end{abstract}

Keywords: Value Relevance; Alternative Accounting Information; Investment Decisions

\begin{abstract}
Abstrak
Distorsi informasi merupakan salah satu risiko akuntansi yang melekat dalam laporan keuangan. Laporan keuangan merupakan salah satu sumber informasi fundamental yang dapat digunakan dalam pengambilan keputusan investasi di Bursa Efek Indonesia. Jika para investor menggunakan informasi ini, maka para investor juga mempunyai risiko yang sama yaitu distorsi informasi yang terdapat dalam laporan keuangan. Oleh karena itu riset ini mencoba melakukan pengujian apakah harga saham lebih dapat dijelaskan melalui informasi akuntansi alternatif atau informasi yang terdapat dalam laporan keuangan. Riset ini dilakukan dengan menggunakan sequential ekspanatory mixed method.
\end{abstract}

* Corresponding author's e-mail: purwantown@yahoo.com

http://openjournal.unpam.ac.id/index.php/JABI 
Jurnal Akuntansi Berkelanjutan Indonesia - Vol. 3, No. 1, Jan 2020 - Nugroho \& Syifaudin

Dengan menggunakan data pada perusahaan yang terdaftar di indeks bisnis 27 yang diuji menggunakan analisis jalur melalui model regresi berganda, hasil riset ini menunjukkan bahwa informasi akuntansi alternative belum dapat menjelaskan variasi perubahan harga saham dibandingkan dengan informasi akuntansi yang terdapat dalam laporan keuangan. Meskipun demikian hasil analisis yang telah dilakukan dengan menggunakan data kualitatif menunjukkan terdapat kesesuaian antara hasil analisis kuantitatif dan analisis kualitatif.

\section{Kata Kunci: Relevansi Nilai; Informasi Akuntansi Alternatif; Keputusan Investasi}

\section{PENDAHULUAN}

FASB melalui SFAC No. 1 menyatakan bahwa para pengguna informasi keuangan yang berasal dari berbagai pihak dapat diklasifikasikan ke dalam dua kelompok pengguna utama. Dua kelompok pengguna utama tersebut adalah investor dan kreditor. Kedua pihak tersebut dianggap mampu mewakili kepentingan seluruh pengguna lain dari laporan keuangan. Kepentingan investor dalam laporan keuangan adalah untuk memastikan bahwa suatu perusahaan mampu menghasilkan keuntungan melalui peningkatan profitabilitas perusahaan. Kepentingan kreditor terhadap informasi akuntansi yaitu untuk memastikan bahwa pengembalian dana yang diberikan melalui ketersediaan kas yang dihasilkan dalam proses bisinis.

Terdapat dua jenis informasi keuangan yang dapat diterima oleh para investor dan kreditor. Kedua jenis informasi tersebut dapat dibedakan dari dua sumber, yaitu informasi yang berasal dari sumber internal perusahaan dan sumber eksternal perusahaan. Informasi keuangan yang berasal dari pihak internal perusahaan merupakan informasi yang diterbitkan oleh perusahaan seperti laporan keuangan tahunan, kuartalan, financial highlight, dan annual report. Informasi keuangan dari pihak eksternal dapat mencakup informasi yang lebih umum seperti kondisi ekonomi, inflasi, tingkat perubahan suku bunga, dan informasi keuangan yang lebih spesifik yang berasal dari para analis laporan keuangan. Informasi keuangan yang berasal dari analis laporan keuangan merupakan informasi keuangan dengan item yang relative sama dengan informasi dalam laporan keuangan yang diadjusted agar lebih merefleksikan kondisi ekonomi perusahaan secara lebih baik. Ketidakpatuhan dan ketidakefisienan BUMN, terutama pada kesalahan pengambilan keputusan investasi pada pengadaan barang dan jasa. Kesalahan pengambilan keputusan ini mungkin juga disebabkan karena informasi yang digunakan saat melakukan pengambilan keputusan. Contoh lain adalah kesalahan penentuan harga beli pada Conoco Philips, kesalahan menentukan pertumbuhan pendapatan pada industri padat modal US Air, kesalahan identifikasi keunggulan kompetitif yang berkelanjutan pada Dexter Shoes.

* Corresponding author's e-mail: purwantown@yahoo.com

http://openjournal.unpam.ac.id/index.php/JABI 
Dalam hal ini terdapat dua informasi yang identik namun berbeda dalam hal pembentukan informasi tersebut. Dua informasi tersebut adalah laporan keuangan dari suatu perusahaan yang mengikuti standar akuntansi yang berlaku dan laporan keuangan tandingan yang berasal dari analis keuangan yang tidak mengikuti standar. Tantangan para pengguna informasi yang berasal dari laporan keuangan adalah distorsi dari kondisi ekonomi yang sesungguhnya. Salah satu penyebab distorsi pada laporan keuangan justru berasal dari standar akuntansi. Standar akuntansi merupakan salah satu penyebab distorsi informasi akuntansi. Akibatnya pergerakan harga saham juga akan terdistorsi, dengan kata lain harga saham tidak mencerminkan realitas ekonomi perusahaan. Untuk meminimalisir hal ini, maka para analis laporan keuangan membuat informasi akuntansi dengan beberapa penyesuaian agar menunjukkan realitas ekonomi yang lebih baik.

Penelitian ini menguji relevansi informasi akuntansi alternatif yang digunakan dalam proses pengambilan keputusan investasi. Penelitian sebelumnya yang menghubungkan peran afektif berupa rekomendasi penasihat (analis) keuangan pada proses pengambilan keputusan investasi yang menyatakan bahwa proses pengambilan keputusan investasi oleh seorang investor juga dipengaruhi oleh berita rekomendasi yang diaksesnya. Hal ini merupakan urgensi penelitian yang membutuhkan suatu investigasi pada peran informasi alternatif sehingga menghasilkan bukti empiris mengenai relevansi informasi akuntansi alternatif yang berasal dari perspektif analisis laporan keuangan yang secara substansi mampu meminimalisir distorsi informasi akuntansi. Tujuan riset ini terletak pada usaha untuk perbaikan secara kontinyu untuk mengatasi distorsi informasi akuntansi guna meningkatkan efisiensi pasar sesuai teori Efficient Market Hypothesis (EMH) khususnya di Indonesia.

\section{KERANGKA TEORITIS DAN PENGEMBANGAN HIPOTESIS}

Teori Hipotesis Pasar Efisien (Efficient Market Hypothesis/EMH) menyatakan bahwa harga pasar merupakan refleksi dari informasi yang tersedia bagi para investor. Efisiensi dalam EMH berarti efisiensi informasi yang terjadi di pasar. EMH mengasumsikan bahwa seluruh investor pada pasar keuangan adalah rasional dan investor tersebut tidak dapat memprediksi pasar di masa yang akan datang menggunakan informasi pasar dari masa lalu dikarenakan adanya informasi yang sempurna di pasar keuangan. Selanjutnya, berfokus pada peran pasar modal, dengan seluruh informasi terkait ekonomi adalah agregat dan perusahaan menggunakan pasar modal sebagai jalur yang efisien terkait pendanaan eksternal.

Laporan keuangan merupakan salah satu cara untuk mengkomunikasikan hasil aktivitas bisnis selama suatu periode. Nilai suatu perusahaan dapat ditentukan melalui kondisi keuangan perusahaan baik yang berasal dari laporan posisi keuangan, laporan laba komprehensif, dan laporan aliran kas. Informasi keuangan yang dibutuhkan oleh pengguna primer laporan keuangan yaitu investor dan kreditor mengacu pada penentuan nilai perusahaan dan kemampuan perusahaan

* Corresponding author's e-mail: purwantown@yahoo.com

http://openjournal.unpam.ac.id/index.php/JABI 
Jurnal Akuntansi Berkelanjutan Indonesia - Vol. 3, No. 1, Jan 2020 - Nugroho \& Syifaudin

dalam melunasi kewajiban yang ada. Nilai perusahaan dapat ditentukan dengan menggunakan informasi laba dan aliran kas. Dua informasi ini juga dapat digunakan sebagai sinyal dalam melihat kualitas laba suatu perusahaan dengan membandingkan dua informasi tersebut.

Pelaporan keuangan bertujuan untuk memberikan informasi tentang situasi dan kondisi perusahaan sehingga dapat digunakan pada proses pengambilan keputusan pada aktivitas investasi dan kredit. Adapun beberapa tujuan dari pelaporan keuangan yang dinyatakan No. 1 salah satunya adalah menyediakan informasi yang berguna dalam pengambilan keputusan investasi dan kredit. Pada No. 2, kualitas utama pelaporan keuangan terdiri dari relevansi dan reliabilitas. Informasi dikatakan relevan bagi investor, kreditor, dan para pengguna lainnya untuk keputusan investasi, kredit, dan keputusan-keputusan yang serupa. Menurut apabila tujuan pelaporan keuangan dilihat dari sisi pemakainya, informasi yang relevan adalah informasi yang berhubungan dengan masalah yang ada ditangan (masalah yang sedang dihadapi). Di masa yang akan datang diharapkan terjadi peningkatan pemahaman mengenai informasi akuntansi terutama jika para akademisi akuntansi (baik sebagai investor maupun potensial investor) dapat menunjukkan cara pengambilan keputusan investasi yang lebih baik berupa penggunaan informasi akuntansi yang lebih relevan terhadap harga saham. [9] menyediakan beberapa hal yang menjadi perhatian untuk para investor dalam melihat kualitas laba yang yang berasal dari beberapa sumber informasi yang relevan seperti laporan akuntansi, catatan atas laporan keuangan, serta sumber lain yang relevan.

Hubungan antara perekonomian dan pasar modal adalah searah. Kondisi pasar modal dan perekonomian berhubungan erat dan harga saham secara konsisten cenderung mengikuti kondisi perekonomian. Mengapa pasar merupakan indikator utama perekonomian? menjelaskan bahwa secara mendasar, harga saham pada saat ini mencerminkan ekspektasi investor tentang perubahan profit perusahaan, sehingga pasar yang salah dalam menilai profit perusahaan akan menimbulkan sinyal yang keliru dalam memprediksi kondisi perekonomian di masa yang akan datang. Meski demikian perlu diketahui bahwa saham perusahaan tidaklah semata-mata ditentukan oleh profit perusahaan semata.

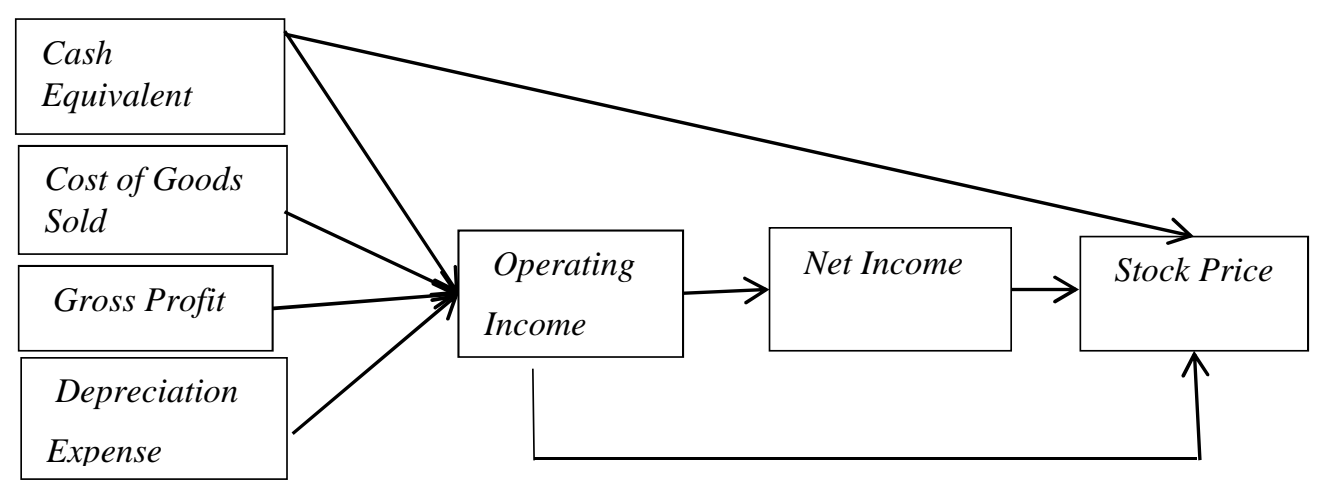

Gambar 1: Kerangka Konseptual

* Corresponding author's e-mail: purwantown@yahoo.com http://openjournal.unpam.ac.id/index.php/JABI 
Jurnal Akuntansi Berkelanjutan Indonesia - Vol. 3, No. 1, Jan 2020 - Nugroho \& Syifaudin

\section{METODE RISET}

Riset ini termasuk jenis riset saintifik dengan dengan studi kausalitas. Belum menggunakan sequential eksplanatory mixed method. Riset dengan menggunakan metode campuran bertujuan meneliti masalah riset dengan menggunakan unsurunsur riset kuantitatif dan kualitatif. Penggabungan riset kuantitatif dan kualitatif disebut dengan istilah triangulasi. Jika ditinjau berdasarkan hasil riset yang akan dicapai, riset ini merupakan riset dasar dengan jenis studi eksplanatori.

Populasi dalam riset ini adalah perusahaan yang terdapat dalam indeks bisnis 27 untuk tahun 2014 dan 2018. Alasan pemilihan indeks ini disebabkan kriteria yang terdapat dalam indeks ini adalah perusahaan yang mempunyai kondisi fundamental yang kuat, likuiditas yang baik, akuntabilitas, serta tata kelola perusahaan yang baik. Teknik yang digunakan dalam pengambilan sampel menggunakan teknik judgement sampling dengan kriteria bahwa perusahaan yang dipilih merupakan perusahaan yang mempunyai aktivitas investasi pada aset keuangan jangka pendek, inventori, dan aset tetap berwujud yang digunakan dalam aktivitas produksi.

Variabel yang digunakan dalam riset ini adalah informasi keuangan yang meliputi: cash equivalent, cost of goods sold, gross profit, beban penyusutan, laba operasional, dan net income yang berasal dari laporan keuangan. Informasi keuangan ini merupakan informasi yang diprediksi dapat mempengaruhi nilai perusahaan yang diproksikan dengan harga saham. Variabel harga saham ditentukan dengan adjusted closing price pada tanggal yang sama dengan penerbitan laporan keuangan.

Analisis data meliputi deskripsi perolehan data serta pengujian statistik secara inferensial. Jenis data yang digunakan dalam riset ini adalah data kuantitatif dengan pengujian statistik parametrik. Jika data riset tidak berdistribusi normal maka pengujian statistik yang digunakan adalah statistik nonparametrik. Pengujian statistik inferensial dilakukan dengan menggunakan analisis jalur dengan dua model regresi OLS. Riset ini ingin melihat mana yang lebih mempunyai kemampuan prediksi yang kuat terhadap harga saham suatu perusahaan. Model empirik yang dipilih adalah model regresi multipel dengan OLS. Model analisis jalur yang digunakan adalah sebagai berikut:

$\mathrm{OI}=\mathrm{b} 1 \mathrm{CE}+\mathrm{b} 2 \mathrm{COGS}, \mathrm{b} 3 \mathrm{GP}, \mathrm{b} 4 \mathrm{DE}+\mathrm{e} .(1)$

$\mathrm{NI}=\mathrm{b} 1 \mathrm{CE}+\mathrm{b} 2 \mathrm{COGS}, \mathrm{b} 3 \mathrm{GP}, \mathrm{b} 4 \mathrm{DE}+\mathrm{b} 5 \mathrm{OI}+\mathrm{e}$. (2)

$\mathrm{SP}=\mathrm{b} 1 \mathrm{CE}+\mathrm{b} 2 \mathrm{COGS}, \mathrm{b} 3 \mathrm{GP}, \mathrm{b} 4 \mathrm{DE}+\mathrm{b} 5 \mathrm{OI}+\mathrm{b} 6 \mathrm{NI}+\mathrm{e}$. (3)

Analisis untuk mengetahui manfaat informasi akuntansi alternatif juga dilakukan dengan model yang sama. Hanya saja data input yang digunakan telah disesuaikan menggunakan prespektif analis agar lebih mencerminkan realitas ekonomi. Riset ini juga menguji pengaruh intervensi variabel laba operasi dan laba bersih dari item yang terdapat di laporan posisi keuangan dan laporan laba/rugi komprehensif.

* Corresponding author's e-mail: purwantown@yahoo.com

http://openjournal.unpam.ac.id/index.php/JABI 
Jurnal Akuntansi Berkelanjutan Indonesia - Vol. 3, No. 1, Jan 2020 - Nugroho \& Syifaudin

\section{ANALISIS DATA DAN PEMBAHASAN}

Data penelitian yang digunakan untuk dianalisis berasal dari laporan keuangan dan ringkasan kinerja perusahaan tercatat yang dipublikasikan oleh pihak Bursa Efek Indonesia. Berdasarkan karakteristik data yang dibutuhkan dalam penelitian, terdapat 17 perusahaan dari 27 perusahaan yang terdaftar pada indeks bisnis 27 di BEI. Kriteria 17 perusahaan tersebut adalah perusahaan yang bergerak dalam industri manufaktur dan selalu memperoleh laba positif.

Cara yang dilakukan untuk membuat data menjadi berdistribusi normal dalam penelitian ini melalui transformasi data dalam bentuk logatitma natural. Berdasarkan hasil analsisi normalitas data setelah melakukan transformasi data ke dalam bentuk logaritma natural, maka data riset menjadi mempunyai distribusi normal. Selanjutnya melakukan analisis statistik inferensial dengan menggunakan analisis jalur melalui tiga model regresi berganda.

Hasil analisis regresi model 1 memberikan koefisien regresi menunjukkan bahwa terdapat satu variabel independent yaitu Gross Profit yang secara statistik signifikan mempengaruhi Operating Income. Sayangnya, hal ini berbeda dengan tiga variabel independent lainnya (Cash Equivalent, Cost Of Goods Sold, dan Depresiation Expense) yang justru secara statistik tidak mempunyai pengaruh yang signifikan terhadap Operating Income. Koefisien regresi dari analisis regresi pada model dua menunjukkan bahwa terdapat satu variabel independent yaitu Beban Depresiasi dan Operating Income yang secara statistik signifikan mempengaruhi Net Income. Sayangnya, hal ini berbeda dengan tiga variabel independent lainnya (Cash Equivalent, Cost Of Goods Sold, dan Gross Profit) yang justru secara statistik tidak mempunyai pengaruh yang signifikan terhadap Net Income.

Berdasarkan tabel koefisien regresi pada model ketiga, hanya terdapat satu variabel independen yang berpengaruh terhadap variabel dependen. Hal ini menunjukkan bahwa informasi keuangan internal yang memnyaui pergerakan data yang sama dengan perspektif pasar adalah variabel Cost Of Goods Sold. Hal ini terlihat melalui tingkat signifikansi yang dihasilkan sebesar 0,004 yang lebih rendah dibandingkan dengan tingkat alpha yang digunakan yaitu sebesar 0,05. Sementara hal variabel independen lainnya yang digunakan dalam model tidak terbukti mempunyai pengaruh yang secara statistik signifikan terhadap Stock Price.

Pengaruh Langsung dan Pengaruh Tak Langsung pada analisis Jalur.

Tiga analisis regresi yang telah dilakukan sebelumnya digunakan untuk menghitung besarnya oengaruh langsung dan pengaruh secara keseluruhan pada analisis jalur. Variabel intervensi dapat dibuktikan salah satunya melalui besarnya pengaruh langsung dan pengaruh taklangsung yang diperoleh dari hasil melakukan analisis statistik dengan menggunakan tiga model analisis regresi.

Pada variabel independen $\mathrm{CE}$, pengaruh langsung yang dihasilkan melalui $(\mathrm{P} 11)=-.456$; pengaruh tak langsung variabel independen CE ke OI ke NI ke SP

* Corresponding author's e-mail: purwantown@yahoo.com

http://openjournal.unpam.ac.id/index.php/JABI 
Jurnal Akuntansi Berkelanjutan Indonesia - Vol. 3, No. 1, Jan 2020 - Nugroho \& Syifaudin

$(\mathrm{P} 1, \mathrm{P} 7, \mathrm{P} 5, \mathrm{P} 6)=.059 * .015 * .834 *-1.596$. Dengan total pengaruh sebesar 0.45718 .

Pada variabel independen COGS, pengaruh langsung yang dihasilkan melalui $(\mathrm{P} 12)=2.213$; pengaruh tak langsung variabel independen COGS ke OI ke NI ke SP $(\mathrm{P} 2, \mathrm{P} 8, \mathrm{P} 5, \mathrm{P} 6)=.047 *-.012 * .834 *$-1.596. Dengan total pengaruh sebesar -0.45718 . Pada variabel independen GP, pengaruh langsung yang dihasilkan melalui $(\mathrm{P} 13)=-1.842$; pengaruh tak langsung variabel independen GP ke OI ke NI ke SP (P3, P9, P5, P6) = .904* .111* .834* -1.596 . Dengan total pengaruh sebesar -1.97572 .

Pada variabel independen DE, pengaruh langsung yang dihasilkan melalui $(\mathrm{P} 14)=-.050$; pengaruh tak langsung variabel independen DE ke OI ke NI ke SP $(\mathrm{P} 4, \mathrm{P} 10, \mathrm{P} 5, \mathrm{P} 6)=-.011 * .056 * .834 *-1.596$. Dengan total pengaruh sebesar 0.04918. Pada variabel independen OI, pengaruh langsung yang dihasilkan melalui $(\mathrm{P} 15)=1.581$; pengaruh tak langsung variabel independen OI ke NI ke SP $(\mathrm{P} 5, \mathrm{P} 6)=.834 *-1.596$. Dengan total pengaruh sebesar 0.249936. Berdasarkan hasil tersebut dapat diketahui bahwa variabel intervening berlaku untuk tiga variabel independent yaitu CE, COGS, dan GP, sementara variabel intervening belum dapat dibuktikan untuk dua variabel lainnya yaitu DE dan OI.

Analisis akuntansi digunakan untuk menyamakan persepsi yang terdapat pada analis laporan keuangan. Analisis ini merupakan informasi akuntansi alternatif yang selanjutnya akan diuji menggunakan statistik parametrik untuk melihat kesesuaian pergerakan data antar variabel. Variabel yang ditentukan sebelumnya dalam penentuan informasi alternatif adalah variabel CE, COGS, GP, dan DE. Variabel yang dipilih untuk lanjutan analisis dilakukan berdasarkan hasil pengujian statistik dengan menggunakan analisis jalur. Variabel yang secara statistik signifikan akan dipilih sebagai variabel yang dianalisis, selanjutnya disesuaikan dan digunakan sebagai proksi informasi akuntansi alternatif. Berdasarkan hasil pengujian statistik yang dilakukan, variabel independen yang akan digunakan sebagai informasi akuntansi alternatif adalah variabel COGS. COGS sangat mempengaruhi Gross Profit, oleh karena itu Gross Profit juga akan disesuaikan. Penyesuaian dilakukan dengan melihat catatan atas laporan keuangan untuk seluruh pembelian inventori yang berasal dari pihak berelasi atau dengan pihak ketiga. Penyesuaian yang dilakukan akan menyebabkan COGS menjadi lebih tinggi daripada yang dilaporkan. Dampaknya, peningkatan COGS akan menurunkan Gross Profit.

Pada variabel COGS ADJUSTED, Pengaruh Langsung (P12 ADJ) sebesar 1.527 dan Pengaruh Taklangsung: COGS ke OI ke NI ke SP (P2, P8, P5, P6) = $0.255 * 0.002 * 0.920 *-1.847$ dengan Total Pengaruh sebesar 1.527. Variabel GP ADJUSTED mempunyai Pengaruh Langsung (P13) sebesar -.012, sedangkan Pengaruh Taklangsung: GP ke OI ke NI ke SP (P3, P9, P5, P6) sebesar .577 * $0.003 * 0.920 *-1.847$, dengan Total Pengaruh sebesar $-0,0091$.

Dari hasil pengujian statistik yang dilakukan dengan menggunakan analisis jalur untuk penyesuaian variabel COGS dan GP menunjukkan bahwa informasi akuntansi alternatif yang ditentukan dengan menyesuaiakan jumlah pembelian kepada pihak berelasi dan pihak ketiga belum mampu mempunyai peran yang

* Corresponding author's e-mail: purwantown@yahoo.com

http://openjournal.unpam.ac.id/index.php/JABI 
dapat dibuktikan secara empiris. Dengan demikian untuk riset selanjutnya dengan topik yang identik mengenai informasi akuntansi alternatif sebaiknya menggunakan penyesuaian yang lebih detail baik yang diperoleh melalui catatan atas laporan keuangan dan data primer yang berasal dari analis laporan keuangan serta pihak internal perusahaan.

Data kualitatif diperoleh melalui informasi yang berasal dari pihak perusahaan sekuritas mengenai beberapa penyesuaian dan asumsi yang digunakan saat melakukan penilaian terhadapo perusahaan. Hasil dari wawancara yang dilakukan oleh periset dengan pihak perusahaan sekuritas memberikan informasi yang berbeda antar satu perusahaan sekuritas satu dengan yang lain. Terdapat perusahaan sekuritas yang secara langsung menggunakan data akuntansi yang terdapat dalam laporan keuangan. Argumennya adalah karena laporan keuangan yang dipublikasikan telah diaudit oleh KAP yang independent dan telah diperiksa oleh OJK. Sementara ada perusahaan sekuritas yang tidak mengetahui penyesuaian yang digunakan saat melakukan penilaian terhadap nilai perusahaan. Hasil dari wawancara yang dilakukan oleh periset dengan pihak perusahaan sekuritas dilakukan melalui kantor cabang perusahaan sekuritas. Hal ini dilakukan karena terdapat keterbatasan sumber pendanaan yang diterima oleh periset, sehingga tidak memungkinkan untuk melakukan wawancara dengan pihak perusahaan sekuritas yang berada di kantor pusat khususnya pada person dalam divisi riset. Dengan demikian penggunaan sequential eksplanatory mixed method dalam penelitian ini menunjukkan kekonsistenan antara data analisis data kuantitatif yang didukung/dikonfirmasi dengan data kualitatif.

\section{KESIMPULAN DAN SARAN}

Riset ini menguji relevansi informasi akuntansi alternatif yang dilihat melalui harga saham perusahaan. Jika informasi alternatif ini mempunyai relevansi nilai untuk harga saham, maka informasi ini mampu menjelaskan perubahan harga saham yang terjadi. Riset ini menggunakan tiga model regresi berganda untuk menguji variabel baik untuk informasi keuangan yang berasal dari laporan keuangan maupun informasi yang berasal dari informasi akuntansi alternatif. Berdasarkan analisis statistik yang dilakukan menunjukkan bahwa informasi alternatif belum mempunyai relevansi nilai yang lebih tinggi terhadap harga saham jika dibandingkan dengan informasi keuangan yang secara formal dipublikasikan melalui laporan keuangan.

\section{DAFTAR PUSTAKA}

A. H. Habbe. (2000). Pengaruh Indikator Makro Ekonomi Terhadap Harga Saham. 
Jurnal Akuntansi Berkelanjutan Indonesia - Vol. 3, No. 1, Jan 2020 - Nugroho \& Syifaudin

D. Wira. (2018). www.juruscuan.com," [Online]. Available:

http://www.juruscuan.com/investasi. Accessed 18 Mei 2018

C. DS and S. PS. (2013). Metodologi Penelitian Bisnis. Jakarta: Salemba Empat.

E. F. Fama. (1970). Efficient Capital Markets: A Review Of Theory And Empirical Work.

F. Ariyanti. www.liputan6.com," 08 Januari 2015. [Online]. Available: https://www.google.co.id/amp/s/m.liputan6.com/amp/2158166. [Accessed 18 Mei 2018]

F. R. David. (2007). Strategic Management: Concepts dan Cases. New York: Prentice Hall.

F. A. S. Board. (1980). Statement of Financial Accounting Concepts, 1980a

H. ES and M. V. Brenda. (1992). Accounting Theory, Chicago: Irwin.

H. I. Wolk, J. L. Dodd and M. G. (2004). Tearney, Accounting Theory: Conceptual Issues in a 7 Political and Economics Environment. SouthWestern, a division of Thomson Learning.

J. E. Pinto, E. Henry, T. R. Robinson and J. D. Stowe. (2010). Equity Assets Valuation. Workbook, Wiley and Sons.

J. Hartono. (2014). Metodologi Penelitian Bisnis: Salah Kaprah dan PengalamanPengalaman. Yogyakarta: BPFE.

J. W. Creswell. (2016). Design: Pendekatan Kualitatif, Kuantitatif, dan Campuran, Yogyakarta: Pustaka Pelajar.

M. W. Keran. (1971). Expectations, Money and Stock Market. EconPapers, vol. 53th, no. Januari 1971, pp. 16-31, 1971.

R. Krishnan and D. Booker. (2002). Investors 'Use of Analysts' Recommendations. Behavioral Research in Accounting 14th Edition, vol. 14th, pp. 129-156. 